\title{
A SUPERLOTAÇÃO DOS PRESÍDIOS E A REINCIDÊNCIA DELITIVA COMO OS PRINCIPAIS PROBLEMAS DE SEGURANÇA PÚBLICA
}

\author{
OVERCROWDING OF PRISONS AND CRIMINAL OFFENSE AS THE MAIN \\ PROBLEMS OF PUBLIC SECURITY
}

\author{
Bruno da Silva Nascimento Soares ${ }^{1}$ \\ Gislaine Silveira Nunes ${ }^{2}$ \\ Aline Andressa Trennepohl Borges ${ }^{3}$ \\ Suelen da Rosa Teixeira ${ }^{4}$ \\ Leandro Luis de Lima ${ }^{5}$ \\ Fabio Rafael Corrêa Oliveira ${ }^{6}$
}

\begin{abstract}
RESUMO- O presente estudo tem como objetivo geral ressaltar informações generalizadas sobre a superlotação dos presídios e suas atribuições estratégicas, assim como estabelecer dados bibliográficos sobre o desenvolvimento desta em relação aos principais problemas de segurança pública. Esse estudo se justifica por apresentar a superlotação dos presídios e a reincidência delitiva como os principais problemas de segurança pública, visto que cada vez mais se alicerça a construção de organizações e também demanda colaborar para a produção do estudo e desenvolvimento de diversas capacidades, com inclusão de profissionais vigentes no trabalho e na formação. Sendo que, por sua vez, apresenta uma contribuição assegurada por meio da utilidade do trabalho a todos, assim como por sua contribuição cumulativa, ou seja, através dos

\footnotetext{
I Graduado em Administração pelo Centro Universitário Metodista (IPA). Pós-graduado em Gestão Prisional pela Faveni. Policial Penal da SEAPEN/RS. E-mail: Bruno.nascimento.adm@gmail.com.

${ }^{2}$ Graduada em Comunicação Social- Habilitada em Relações Públicas pela Universidade Federal do Rio Grande do Sul (UFRGS). Pós-graduada em Perfis criminais e comportamentais pela IBRA. Policial Penal da SEAPEN/RS. E-mail:gislainesilveirar6@gmail.com.

${ }^{3}$ Graduada em Ciências Contábeis pela Universidade de Passo Fundo(UPF). Pós-graduada em Segurança Pública pela Faculdade Alfamérica. Policial Penal da SEAPEN/RS. E-mail: aline_atb@hotmail.com.

${ }_{4}$ Graduada em Gestão Ambiental pela Universidade da Região da Campanha( URCAMP). Pós-graduada em Perícia e Auditoria Ambiental pela Uninter. Pós-graduada em Segurança Pública e Cidadania pela IBRA. Policial Penal da SEAPEN/RS. E-mail:suelen.teixeira@hotmail.com.

5 Graduado em Segurança Pública pela Universidade Luterana do Brasil- ULBRA.Especialista em Direito Criminal pela Uniasselvi. Policial Penal SEAPEN/RS. E-mail: leandro-luis@susepe.rs.gov.br.

${ }^{6}$ Graduado em Gestão Pública pela Faculdade Cruzeiro do Sul. MBA em gestão Pública pela Faculdade Cruzeiro do Sul. Policial Penal SEAPEN/RS. E-mail: rafael.oliveira.msn@hotmail.com.
} 
dados que este agrega ao grupo de conhecimento científico da temática. E, por fim, por meio do ineditismo da matéria ou da aproximação e apoio a ultrapassagem de ausências no estudo. Considerando todos os objetivos propostos inicialmente, pode ser concluído que depois das análises e estudos relacionados a essa temática, a abordagem desejada foi abrangida com sucesso, ressaltando de maneira geral todos os pontos necessários para que seja atingido um pensamento sobre o tema de modo preciso.

Palavras-chave: Segurança pública. Superlotação em presídios. Sistema prisional.

ABSTRACT - The present study has the general objective of highlighting generalized information about the overcrowding of public prisons and their strategic attributions, as well as establishing bibliographic data on its development in relation to the main security problems. This study is justified by presenting an overcrowding of prisons and criminal recidivism as the main problems of public security, since it is increasingly based on the construction of associations and also demands to collaborate for the production of the study and development of several functions, with inclusion of current professionals at work and in training. Being that, in turn, it makes a guaranteed contribution through the usefulness of the work to all, as well as by its cumulative contribution, that is, through the data that it adds to the group of scientific knowledge of the theme. And, finally, through the originality of the material or the approximation and support of overcoming absences in the study. The objective of all the proposed objectives, it can be concluded that after the analysis and studies related to this theme, the desired approach was successfully covered, highlighting in general all the points dealt with in order to achieve a thought on the theme in a precise way.

Keywords: Public security. Overcrowding in prisons. Prison system.

\section{INTRODUÇÃO}

A ordenação prisional brasileira vive um estado caótico. Apenados são amontoados em celas coletivas em condições desumanas e degradantes que remetem à triste memória do escravagismo dos séculos XVI a XIX, aos campos de concentração dos nazistas na Segunda Guerra Mundial ou aos gulags da extinta União das Repúblicas Socialistas Soviéticas. A falta de vagas no sistema penitenciário é notória, de forma que o apenado cumpre sua pena em condições que ferem a distinção humana, em completo afronto ao intrépido no Princípio no 7.210, de II de julho de 1984, Lei de Execução Penal (LEP) (BRASIL, 1984).

A Anistia Internacional, ao corporificar uma informação sobre o estado dos presídios

brasileiros destacou que as prisões são uma masmorra, com condições de animais. São um 
armazém de seres humanos em péssimas condições. Há um estado generalizado de superlotação, de péssimas condições de saúde e de higiene.

São recorrentes as denúncias de esgoto dentro das celas e de banheiros, quando existentes, em péssimas condições de utilização. Epidemia de ratos, baratas, bactérias, sendo um local perfeito para que doenças como febre héctica, pneumonia, alergias, aids, treponemíase etc. se espalhem como rastilho de pólvora. $\mathrm{O}$ tratamento odontológico se limita e o trabalho pedagógico do apenado quase não existe.

Além da fraca estrutura física, o sistema de energia não separa os apenados por tipo de delito, criando verdadeiras escolas do crime dentro do local prisional. "Ladrões de galinha" são enclausurados com líderes de organizações criminosas, o que leva, fatalmente, àqueles serem aliciados por esses, para a execução de crimes mais bárbaros e cruéis.

Há um sistema que não recupera o encarcerado e o pune duas vezes: uma ao tolher sua liberdade, e outra ao privá-lo de sua distinção. E lhe proporciona a passividade do crime, conciliação para que o apenado se torne um profissional nos muitos costumes delitivos.

Nesse entrecho, e com o fito de levar do Estado o peso da prestação de serviços públicos constitucionalmente definidos como fundamentais, foi sancionado o Princípio n⿳o Ir.079, de 30 de dezembro de 2004, que institui códigos gerais para licitação e contratação de sociedade público-privada no meio público. O aludido princípio a define como uma contratação administrativa de concessão, na forma patrocinada ou administrativa (BRASIL, 2004).

O presente estudo tem como objetivo geral ressaltar informações generalizadas sobre a superlotação dos presídios e suas atribuições estratégicas, assim como estabelecer dados bibliográficos sobre o desenvolvimento desta em relação aos principais problemas de segurança pública. Para a conclusão e alcance do objetivo geral deste, serão abordados os seguintes quesitos com total exatidão para que a finalidade seja estabelecida corretamente: apresentar o conceito e os tipos de penitenciárias no Brasil; contextualizar a história do sistema prisional; enaltecer a reincidência criminal no âmbito nacional.

Visando sempre os objetivos específicos para a discussão do tema, assim agregando valores e atribuindo condições estratégicas de maneira geral, o trabalho parte do seguinte 
problema de pesquisa: como se da a superlotação dos presídios como problema de segurança pública?

Esse estudo se justifica por apresentar a superlotação dos presídios e a reincidência delitiva como os principais problemas de segurança pública, visto que cada vez mais se alicerça a construção de organizações e também demanda colaborar para a produção do estudo e desenvolvimento de diversas capacidades, com inclusão de profissionais vigentes no trabalho e na formação. Sendo que, por sua vez, apresenta uma contribuição assegurada por meio da utilidade do trabalho a todos, assim como por sua contribuição cumulativa, ou seja, através dos dados que este agrega ao grupo de conhecimento científico da temática. E, por fim, por meio do ineditismo da matéria ou da aproximação e apoio a ultrapassagem de ausências no estudo.

Foi utilizada a metodologia de pesquisa literária, extraída de artigos sobre o tema, a coleta de dados foi realizada através de vários artigos e sites pesquisados, referentes ao tema e assuntos relacionados. O método utilizado foi a revisão de literatura, onde os critérios de inclusão são estudos relacionados à “A superlotação dos presídios e a reincidência delitiva como os principais problemas de segurança pública”, para um bom trabalho. A seleção dos artigos foi realizada com a avaliação do título, seguida pela leitura dos resumos. Os critérios de inclusão dos artigos, inicialmente para a revisão levaram em conta textos em português.

\section{DESENVOLVIMENTO \\ I.I Conceito e tipos de penitenciárias no Brasil}

De acordo com Capez (2016), penitenciária é a supressão de liberdade de determinada ordem do consentimento habilitado ou em caso de flagrante delito. Similarmente é um "cautério" imposto pelo Estado ao condenado pela execução de inobediência penal, para que esse possa reabilitar visando reformar a ordem jurídica violada (CAPEZ, 2016).

É a determinação oficial de tomada ou presa, ao qual deverão ser recolhidos os seres humanos condenados pela Justiça, por terem cometido um tipo de delito ou inobediência em oposição as leis do Estado. Os estabelecimentos penais destinam-se ao condenado, ao domesticado à providência de segurança, ao encarcerado temporário e ao egresso. $\mathrm{O}$ mesmo 
conjunto arquitetônico será capaz de conter estabelecimentos de finalidade diversa a partir de que conforme isolados (PENITENCIÁRIA, 20I6).

Os principais tipos de estabelecimentos penais são: cadeias públicas, penitenciárias, colônias agrícolas ou industriais, casas do Albergado, hospitais de custódia e tratamento psiquiátrico. O Brasil tem 821 cadeias públicas, que são destinadas à retirada de indivíduos presos em período temporário. O que define os tipos de estabelecimentos penais principalmente é a intenção semelhante das unidades.

De acordo com a LEP, penitenciária é o elemento prisional destinado aos condenados a realizar pena, enquanto as colônias agrícolas, ou industriais são destinadas aos presos da semiaberta e a casa do albergado, aqueles em prisão aberta. Detentos provisórios precisam esperar a sentença em grade pública. Há também os hospitais de custódia, no qual precisa realizar providência de segurança quem cometeu crime por uma dificuldade intelectual e foi, dessa forma, considerado inimputável ou semi-imputável (CNJ, 2016).

De acordo com Alípio Silveira, a superlotação prejudica a concessão da vantagem, que bem como a ambição preliminar a desocupação de cela separadas das outras, uma vez que o

contato com mais presos, ainda que em tempo ínfimo, acarreta graves inconvenientes à prisão de semiliberdade. Em outras palavras, não iria observar-se uma das regras mínimas em prisão de abrigo (SILVEIRA, 20Io).

Datado o publicado, o Brasil tem vários estabelecimentos penais para que seja terminada determinada pena, haja averiguado, o tipo de crime que o detento irá cumprir.

\subsection{Histórico do sistema prisional}

Em tempos atrás, os réus não eram condenados especialmente pela redução da liberdade por um tempo. Eram punidos com morte, suplício, açoite, amputação de membros, funções forçadas etc. Para proporcionar a correção imposta, permaneciam presos ao longo de um tempo preciso enquanto aguardava a sentença. Dessa maneira, o encarceramento era um meio, não o fim da correção. Nesse entrecho, não existia receio com a qualidade do ambiente nem sequer com a própria saúde do encarcerado. 
Por meio do século XVIII, a prisão torna-se, por isso, essência do sistema punitivo. A intenção do encarceramento passa a ser insular e restabelecer o desobediente. A atual reclusão insalubre, capaz de acamar seus hóspedes e matá-los antes do momento, como simples acidental de um processamento punitivo experiente na pena física, apresenta a ideia de uma determinação pública, íntegra, regulamentada, higiênica, intransponível, capaz de proteger-se o delito e ressocializar quem o comete. O processamento passa pela oscilação histórica significativa, apesar de que várias vezes essas secundinas qualidades apenas estejam asseguradas no papel, dessa forma, frequentemente, o progresso da prisão é agregado ao humanismo.

O sistema prisional atual, em vez de oferecer a recuperação do encarcerado, acaba por fazer novos infratores, mais violentos e revoltados com a sociedade. A falta de esboços de ressocialização para os detentos e as próprias condições indispensáveis de uma economia avançada dos presídios torna a reclusão um local suscetível e auspicioso à epidemia de doenças e todo tipo de deterioração humana, no momento em que deveria proporcionar as devidas assistências previstas no princípio, que visa a garantia mínima dos Direitos Humanos.

Dessa maneira, o dor de parcialidade que um encarcerado experimenta é um dos motivos que mais pode reintegrar indomável sua natureza. No momento em que se vê dessa maneira publicado ao princípio que não ordenou nem sequer mesmo previu, ele entra em estado habitual de selvajaria em oposição a tudo que o cerca; não pensa mais ter sido criminoso, acusa a própria justiça (FOUCAULT, 2009).

Essa falta de qualidade pública, dentre tantas mais complicações, demonstram o fragor do atual sistema penitenciário brasileiro. Essa situação avaliativa que são submetidas aos presos, sem que ocorra de fato a ressocialização e, então, incentivando o retorno ao criminalismo, se leva a observar o menosprezo com os direitos humanos. A prisão torna possível, ou seja, favorece a disposição do meio de delinquentes, solidários entre si, hierarquizados, concluído para todas as cumplicidades futuras (FOUCAULT, 2009). 


\section{I.3 A reincidência criminal em âmbito nacional}

A abordagem da obstinação criminal no Brasil passa principalmente por sua natureza jurídica. É definida no texto 63 do Código Penal nos termos em que se verifica a obstinação quando o intermediário comete novo crime, depois de seguir em julgado a voto que, no país ou no exterior, o tenha condenado por crime anterior.

Então, para se idealizar a obstinação no meio jurídico-penal é essencial um voto condenatório transitado em julgado, ou seja, uma danação por um crime à qual não caiba mais recurso. E a acidental obstinação influencia as vantagens a quem possui direito.

As pesquisas sociológicas no Brasil sobre obstinação criminal realizadas até o momento não se pautaram impreterivelmente por análogo conceituação jurídica. O desapontamento de rarefeitos, estas pesquisas privilegiaram o cômputo da obstinação no espaço penitenciário. Adiante apresenta-se o detalhamento metodológico de cada um deles.

\subsection{O estudo de Adorno e Bordini}

A pesquisa de Adorno e Bordini (1986) se concentrou na obstinação criminal no estado de São Paulo. O estudo perpassou por dois aspectos: avaliar a relevância da obstinação penitenciária e traduzir o perfil comunitário dos reincidentes, contrastando-os com os não reincidentes. A verificação dos dados biográficos foi preciso para o entendimento do perfil comunitário das pessoas observadas, bem como dados jurídico-processuais e da trajetória institucional que se referem a entradas anteriores nas unidades prisionais, idade da primeira chegada na prisão e penitenciária, recomendação do comportamento regularizador, orientações colegial e profissional, circunstâncias da liberdade e obstinação.

Para formação do banco de dados foi necessário utilizar como fontes as variáveis jurídico-processuais e os dados biográficos foram extraídos do setor de cadastragem criminal da Coordenadoria dos Estabelecimentos Penitenciários do Estado de São Paulo (Coespe); os dados relativos ao ensino, profissionalização e trabalho foram colhidos juntamente ao setor de profissionalização. Fundamental expressar que a fonte que tirou todo ligamento entre estes 
arquivos foi o algarismo de matrícula na Coespe, por meio da referência das fichas cadastrais. A escolha pelas fichas cadastrais em vez dos prontuários criminais, judiciais e penitenciários deu-se na providência em que se verificaram complicações de fidedignidade destes últimos.

Adorno e Bordini (1986) realizaram o estudo acompanhando as pessoas no período de janeiro de 1974 a dezembro de 1985 , verificando, ao final, quantas daquelas pessoas retornariam ao sistema penitenciário ou cadeias públicas do estado de São Paulo. A tarifa de obstinação penitenciária encontrada por eles foi de $46,03 \%$.

\subsection{2 $\mathrm{O}$ estudo de Julita Lemgruber}

A pesquisa de Lemgruber (1989) se concentrou no estado do Rio de Janeiro e foi executada em 1988, tendo como propósito dimensionar a obstinação penitenciária no predito estado, bem como traçar o perfil dos reincidentes e contrastá-lo com o dos não reincidentes. $\mathrm{O}$ estudo foi realizado no Departamento do Sistema Penal (Desipe), envolvendo a verificação quantitativa de 5\% dos presos permanentes do estado que naquela época totalizavam 8.269 presos e 25 I presas. A eventualidade de consumo dos dados a partir dos prontuários móveis que acompanham os detentos em seu curso carcerário foi descartada, uma vez que eles não possuíam as informações necessárias para o estudo. Além disso, foi considerado que na seção jurídica do Desipe as informações não estavam atualizadas. Por essas causas, optou-se por usar uma amostra de detentos para o estudo. Os questionários permitiram traçar um perfil comunitário dos reincidentes e contrastá-lo com o perfil dos não reincidentes. Dessa maneira, foi possível identificar similaridades e diferenças, e por isso esclarecer as causas que levaram à obstinação penitenciária.

Foram colhidos dados que possibilitaram a afoiteza das qualidades biográficas mais objetivas (idade, etnia, escolaridade etc.) e informações reveladoras da vida do detento, como passagem por instituições, início no mundo do crime e início no mundo do trabalho. Por meio dos resultados se atraiu a tarifa de obstinação de 30,7\%, sendo relativo aos homens de 31,3\% e às mulheres de $26 \%$. 


\subsubsection{O estudo do Ipea}

O primeiro estudo sobre obstinação criminal feita pelo Instituto de Pesquisa Econômica e Aplicada (Ipea, 2015) foi coordenada por Almir de Oliveira Junior, tendo como propósito entregar uma exposição da obstinação criminal no Brasil por meio da coleta de dados em algumas unidades da coligação. $O$ trabalho executado optou pelo conceito de obstinação legal. O estudo se ocupa, então, dos casos em que há condenações de uma pessoa em distintas ações penais, ocasionadas por fatos variados.

A pesquisa optou por adotar metodologia quantitativa complementada por metodologia qualitativa na intenção de escavar ideias de recuperação comunitária. Entendeu-se que seria fundamental dentro do estudo escavar o entendimento a respeito dos programas de ressocialização. Houve o objetivo de supervisionar em que providência tais programas desenvolvidos nos âmbitos dos estados brasileiros estariam se aproximando ou se afastando da canalização à recuperação comunitária norteada tanto pelo Departamento Penitenciário Nacional (Depen) quanto pelo CNJ, quais técnicas adotadas, qual intenção das mesmas e, o mais fundamental, em que equivalência estaria impactando a obstinação criminal.

Os dados da obstinação foram arranjados nas varas de execução criminal em cinco

estados: Paraná, Minas Gerais, Rio de Janeiro, Alagoas e Pernambuco. A tarifa de obstinação encontrada foi de $24,4 \%$. A faixa etária que predominou entre os apenados na hora do crime foi a de 18 a 24 anos, com 42,1\% do completo de casos. Com correlação ao perfil dos apenados, podese expressar que a maior parte dos reincidentes era da etnia/cor branca, enquanto entre os não reincidentes a maior parte era preta ou parda; em correlação à volúpia havia preeminência de homens em correlação a mulheres. Resumindo, os indivíduos reincidentes da amostra encontrada pelo estudo Ipea eram de jovens de cor branca e de baixa escolaridade.

\section{CONCLUSÃO}

Considerando todos os objetivos propostos inicialmente, pode ser concluído que depois das análises e estudos relacionados a essa temática, a abordagem desejada foi abrangida com 
sucesso, ressaltando de maneira geral todos os pontos necessários para que seja atingido um pensamento sobre o tema de modo preciso.

A inclusão dos conceitos de segurança pública permite uma abrangência muito maior sobre a perspectiva de cada determinação. Enaltecendo de forma clara e precisa sobre a expressão, possibilitando, dessa forma, um entendimento bastante amplo sobre a questão.

Podendo considerar então que o ordenamento jurídico pátrio antevê muitas formas de proteção e óbolo ao detento, assegurando os seus direitos essenciais, como o respeito à distinção do indivíduo humano, e similarmente estabelece formas de impulso a sua recuperação a sociedade depois de o cumprimento da sua pena, com políticas educacionais e de trabalho.

Não obstante, Estado também não conseguiu atingir a finalidade esperada em princípio, não fornecendo as condições necessárias para a prática de programas de reeducação do encarcerado, para que seja possível mostrar a eles uma outra existência distinta daquela do criminalismo.

$\mathrm{Na}$ verdade, o que pode se analisar nos estabelecimentos prisionais por todo o Brasil é uma existência bem distante do prescrito em princípio. Os apenados vivem em uma situação

prisional sub-humana, com celas superlotadas, sem condições básicas de higiene e relaxamento, sem refeição adequada, sem assistência médica, sem uma equipe de servidores preparados e em algarismo satisfatório, e sem qualquer acesso a eventualidade de trabalhar ou ganhar qualquer ensino educacional.

\section{REFERÊNCIAS}

ADORNO, S.; BORDINI, E. Reincidência e reincidentes penitenciários em São Paulo - 1974 a 1985. Revista Brasileira de Ciências Sociais, 1986.

BRASIL. Lei no 7.210, de il de julho de 1984. Lei de Execução Penal. Brasília: Poder Legislativo, 1984. Disponível em: https://bit.ly/2rojp7p. Acesso periódico durante o desenvolvimento do trabalho.

BRASIL. Lei no II.079, de 30 de dezembro de 2004. Institui normas gerais para licitação e contratação de parceria público-privada no âmbito da administração pública. Brasília: Poder 
Legislativo, 2004. Disponível em: https://bit.ly/ıqCoSXQ. Acesso periódico durante o desenvolvimento do trabalho.

CAPEZ, F. Direito penal. 2016. Disponível em: http://bit.ly/2ZtNpt3. Acesso periódico durante o desenvolvimento do trabalho.

CNJ. Tipos de penitenciária no Brasil. 2016. Disponível em: http://bit.ly/2vnrxkU. Acesso periódico durante o desenvolvimento do trabalho.

FOUCAULT, M. Vigiar e Punir: nascimento da prisão. Rio de janeiro: Vozes, 1984.

IPEA - Instituto de Pesquisa Econômica Aplicada. Reincidência criminal no Brasil. Brasília: Ipea, 2015.

LEMGRUBER, J. Reincidência e reincidentes penitenciários no sistema penal do Estado do Rio de Janeiro. Revista da Escola de Serviço Penitenciário do Rio Grande do Sul, 1989.

PENITENCIÁRIA. 2oi6. Disponível em: http://bit.ly/2UWojB6. Acesso periódico durante o desenvolvimento do trabalho.

SILVEIRA, A. Prisão albergue e regime semi-aberto. Rio de Janeiro: Brasilivros, 2010. 